\title{
EURO-CORDEX: new high-resolution climate change projections for European impact research
}

\author{
Daniela Jacob · Juliane Petersen · Bastian Eggert $\cdot$ Antoinette Alias · Ole Bøssing Christensen • \\ Laurens M. Bouwer • Alain Braun · Augustin Colette • Michel Déqué • Goran Georgievski • \\ Elena Georgopoulou • Andreas Gobiet · Laurent Menut • Grigory Nikulin · Andreas Haensler • \\ Nils Hempelmann · Colin Jones · Klaus Keuler · Sari Kovats • Nico Kröner • Sven Kotlarski • \\ Arne Kriegsmann - Eric Martin • Erik van Meijgaard • Christopher Moseley • Susanne Pfeifer • \\ Swantje Preuschmann - Christine Radermacher - Kai Radtke - Diana Rechid - Mark Rounsevell • \\ Patrick Samuelsson - Samuel Somot · Jean-Francois Soussana • Claas Teichmann • Riccardo Valentini • \\ Robert Vautard $\cdot$ Björn Weber $\cdot$ Pascal Yiou
}

Received: 31 January 2013/Accepted: 20 June 2013/Published online: 23 July 2013

(c) The Author(s) 2013. This article is published with open access at Springerlink.com

\begin{abstract}
A new high-resolution regional climate change ensemble has been established for Europe within the World Climate Research Program Coordinated Regional Downscaling Experiment (EURO-CORDEX) initiative. The first set of simulations with a horizontal resolution of $12.5 \mathrm{~km}$ was completed for the new emission scenarios RCP4.5 and RCP8.5 with more simulations expected to follow. The aim of this paper is to present this data set to the different communities active in regional climate modelling, impact
\end{abstract}

Electronic supplementary material The online version of this article (doi:10.1007/s10113-013-0499-2) contains supplementary material, which is available to authorized users.

D. Jacob $(\bowtie) \cdot$ J. Petersen $\cdot$ B. Eggert · A. Haensler .

N. Hempelmann - A. Kriegsmann - C. Moseley - S. Pfeifer ·

S. Preuschmann $\cdot$ D. Rechid $\cdot$ C. Teichmann $\cdot$ B. Weber

Climate Service Center (CSC), Helmholtz-Zentrum Geesthacht,

Fischertwiete 1, 20095 Hamburg, Germany

e-mail: daniela.jacob@hzg.de

D. Jacob · J. Petersen $\cdot$ C. Moseley $\cdot$ C. Radermacher .

D. Rechid · C. Teichmann

Max Planck Institute for Meteorology (MPIM), Bundesstr. 53,

20146 Hamburg, Germany

A. Alias - A. Braun - M. Déqué - E. Martin - S. Somot Météo-France/CNRS, Centre National de Recherches Météorologiques (CNRM-GAME), 42, Avenue Gaspard

Coriolis, 31057 Toulouse Cedex 1, France

O. B. Christensen

Danish Climate Centre, Danish Meteorological Institute (DMI),

Lyngbyvej 100, 2100 Copenhagen, Denmark

\section{M. Bouwer}

Institute for Environmental Studies, Vrije Universiteit, De Boelelaan 1087, 1081 HV Amsterdam, The Netherlands assessment and adaptation. The EURO-CORDEX ensemble results have been compared to the SRES A1B simulation results achieved within the ENSEMBLES project. The large-scale patterns of changes in mean temperature and precipitation are similar in all three scenarios, but they differ in regional details, which can partly be related to the higher resolution in EURO-CORDEX. The results strengthen those obtained in ENSEMBLES, but need further investigations. The analysis of impact indices shows that for RCP8.5, there is a substantially larger change projected for temperature-based indices than for RCP4.5. The difference is less pronounced for precipitation-based

L. M. Bouwer

Deltares, PO Box 177, 2600 MH Delft, The Netherlands

A. Colette

Institut National de l'Environnement Industriel et des Risques

(INERIS), 60550 Verneuil-en-Halatte, France

G. Georgievski · K. Keuler · K. Radtke

Environmental Meteorology, Brandenburg University of

Technology, Burger Chaussee 2, 03013 Cottbus, Germany

E. Georgopoulou

Institute for Environmental Research and Sustainable

Development (IERSD), National Observatory of Athens,

11810 Thissio, Greece

A. Gobiet

Wegener Center for Climate and Global Change and Institute for Geophysics, Astrophysics, and Meteorology, University of Graz, Brandhofgasse 5, $8010 \mathrm{Graz}$, Austria

L. Menut

Laboratoire de Météorologie Dynamique (IPSL), Ecole

Polytechnique, 91128 Palaiseau Cedex, France 
indices. Two effects of the increased resolution can be regarded as an added value of regional climate simulations. Regional climate model simulations provide higher daily precipitation intensities, which are completely missing in the global climate model simulations, and they provide a significantly different climate change of daily precipitation intensities resulting in a smoother shift from weak to moderate and high intensities.

Keywords Regional climate change - Impact indices . EURO-CORDEX - Heat wave $\cdot$ Heavy precipitation .

Dry spells

\section{Introduction}

Climate impact assessments and the development of regional to local-scale adaptation strategies require the availability of high-resolution climate change scenarios, including an assessment of their robustness and their inherent uncertainties. The WCRP Coordinated Regional Downscaling Experiment (CORDEX, http://wcrp-cordex. ipsl.jussieu.fr/; Giorgi et al. 2006) provides an internationally coordinated framework to improve regional climate scenarios. This includes harmonisation of model evaluation activities in the individual modelling centres and the generation of multi-model ensembles of regional climate projections for the land-regions worldwide.

As part of the global CORDEX framework, the EUROCORDEX initiative (http://www.euro-cordex.net/) provides regional climate projections for Europe at $50 \mathrm{~km}$ (EUR-44) and $12.5 \mathrm{~km}$ (EUR-11) resolution, thereby complementing coarser resolution data sets of former activities like, e.g., PRUDENCE and ENSEMBLES. The regional simulations are downscaling the new CMIP5

G. Nikulin · C. Jones · P. Samuelsson

Swedish Meteorological and Hydrological Institute (SMHI),

Folkborgsvägen 17, 60176 Norrköping, Sweden

S. Kovats

London School of Hygiene and Tropical Medicine,

15-17 Tavistock Place, London WC1H 9 SH, UK

\section{N. Kröner $\cdot$ S. Kotlarski}

Institute for Atmospheric and Climate Science, ETH Zurich,

Universitätsstraße 16, 8092 Zurich, Switzerland

E. van Meijgaard

Royal Netherlands Meteorological Institute (KNMI),

Wilhelminalaan 10, 3732 GK De Bilt, The Netherlands

\section{Rounsevell}

David Kinloch Michie Chair of Rural Economy \&

Environmental Sustainability, Institute of Geography \& the

Lived Environment, School of GeoSciences, The University of

Edinburgh, Drummond Street, Edinburgh EH8 9XP, UK global climate projections (Taylor et al. 2012) and the new representative concentration pathways (RCPs) (Moss et al. 2010; van Vuuren et al. 2011). Twenty-six modelling groups contributing 11 different regional climate models, partly in different model configurations, actively support EURO-CORDEX.

In its initial phase, EURO-CORDEX mainly focussed on model evaluation in present-day climate (e.g., Vautard et al. 2013; Kotlarski et al. 2013). So far more than 30 evaluation simulations have been conducted. Further activities include the coordinated analysis of future climate simulations, the joint analysis of dynamical and empiricalstatistical methods and the design of suitable bias correction techniques to tailor EURO-CORDEX data for direct application in climate impact research. Particular emphasis is put on the construction of a simulation matrix that covers uncertainty in emission scenarios, the driving global climate model and the downscaling method in the best affordable manner. Here, we present the first results of the high-resolution (EUR-11) future climate simulations from EURO-CORDEX.

We used for comparison the results obtained from the regional climate projections in the FP6 ENSEMBLES project (Hewitt and Griggs 2004; van der Linden and Mitchell 2009). A number of regional limited-area models were used to downscale transient global climate projections over Europe at a 25 and $50 \mathrm{~km}$ resolution over the second half of the twentieth century and along the twenty-first century. The ENSEMBLES climate projections were carried out under the assumptions of the Special Report on Emission Scenario (SRES) A1B scenario (IPCC 2000). This scenario follows the storyline of the IPCC family of A1 scenarios. It assumes a rapid economic growth and development of technologies, with a worldwide population peaking in the middle of the twenty-first century, and a

J.-F. Soussana

INRA, UR874, Grassland Ecosystems Research (UREP), Clermont-Ferrand, France

R. Valentini

Department of Forest Science and Environment,

University of Tuscia, Viterbo, Italy

R. Valentini

Euro-Mediterranean Center for Climate Change, Via De Lellis, 01100 Viterbo, Italy

R. Vautard · P. Yiou

Laboratoire des Sciences du Climat et de l'Environnement, IPSL, CEA/CNRS/UVSQ, Gif sur Yvette, France 
balanced use of energy resources. This scenario leads to a rapid increase in fossil $\mathrm{CO} 2$ emissions until 2050 and a decrease afterwards. As compared to other SRES scenarios, the $\mathrm{CO} 2$ emissions lie in the middle of the scenario range.

EURO-CORDEX scenario simulations use the new Representative Concentration Pathways (RCPs) defined for the Fifth Assessment Report of the IPCC (Moss et al. 2010). In contrast to the SRES scenarios, RCP scenarios do not specify socioeconomic scenarios, but assume pathways to different target radiative forcing at the end of the twentyfirst century. For instance, scenario RCP8.5 assumes an increase in radiative forcing of $8.5 \mathrm{~W} / \mathrm{m} 2$ by the end of the century relative to pre-industrial conditions.

A comparison between the climate effects of SRES and RCP scenarios (Rogelj et al. 2012) indicates that the A1B scenario leads to a global mean temperature increase in the likely range of $2.8-4.2{ }^{\circ} \mathrm{C}$, which approximates to RCP6 and lies clearly between RCP4.5 and RCP8.5.

The aim of the present study is to present a new highresolution $(12.5 \mathrm{~km})$ data set from a multi-model multiscenario ensemble of regional climate simulations for impact research. Such a high resolution has not been reached before in previous climate model projections. The ENSEMBLES project covered RCM simulations for Europe with a maximum resolution of $25 \mathrm{~km}$, and in PRUDENCE, all simulations were done on a $50 \mathrm{~km}$ grid.

The analysis carried out here is directed towards regional climatic changes in Europe, addressing the differences of mean changes in annual mean temperature and total precipitation for the scenarios A1B, RCP4.5 and $\mathrm{RCP} 8.5$. In addition to the mean values, a range of climate indices important for climate impact studies in different sectors were calculated for sub-regions of Europe including: heavy precipitation events, dry spells and heat waves.

\section{Experimental setup, statistical methods and definitions of indices}

\section{Experimental setup}

In total, nine simulations have been done for RCP4.5 and ten for RCP8.5. They were all performed on the EURO-CORDEX domain, expect one simulation, which covered only the MED-CORDEX domain. The size and location of the CORDEX domains can be seen on the CORDEX web page (http://wcrp-cordex.ipsl.jussieu.fr/). The EURO-CORDEX domain covers all countries in the European Union, but it does not map perfectly to the Europe region defined for the IPCC Fifth Assessment Report. For the eastern part of Turkey, unfortunately, no regional model projections are available.
A summary of the grid configuration and differences in the parameterisation schemes for the participating regional models (ALADIN5.1: Colin et al. 2010, Herrmann et al. 2011, CCLM: Rockel et al. 2008, HIRHAM: Christensen et al. 1998, RACMO2: Meijgaard van et al. 2012, RCA4: Samuelsson et al. 2011, Kupiainen et al. 2011, REMO: Jacob et al. 2012, WRF Version 3.3.1: Skamarock et al. 2008) is given in the supplementary material (Table s1). The RCP scenarios, the driving GCMs and the driven RCMs as well as the simulation length are listed in the supplementary material (Table s2a). Seven different RCMs and five different GCMs have been used in this study. Two of the RCMs were driven by four/five different GCMs; five GCM-RCM chains did simulate both RCP scenarios. They all provide data at least until the mid of the century. Eight RCP4.5 simulations and nine RCP8.5 simulations had reached the end of the century.

Two additional sensitivity studies have been performed to study the influence of the smaller domain size used by one model (supplementary material, Figure s6) and the effect of using one RCM more often than others (supplementary material, Figure s7).

From the ENSEMBLES data set, 20 transient RCM simulations reaching the end of the century are used for most of the analysis (supplementary material, Table s2b). Maximum and minimum temperature values were only available from nine simulations. The ensemble includes simulations on 50 and $25 \mathrm{~km}$ grid scale, but most simulations were carried out on a $25 \mathrm{~km}$ grid (16 out of 20 and 7 out of 9). The coarser resolution simulations were included to enlarge the sample size for the statistical analyses. A sensitivity study using only the $25 \mathrm{~km}$ simulations for the analyses of changes in the mean fields of temperature and precipitation and in the indices showed that there are only minor differences in the horizontal pattern of the meteorological parameters as well as in the regions with a significant and/or robust change (not shown).

\section{Statistical methods}

All regional changes have been analysed for the land areas of the EURO-CORDEX domain using daily data for three time periods: 1971-2000, 2021-2050 and 2071-2100. For changes in all outcome measures (mean annual and seasonal temperature, total annual and seasonal precipitation, heavy precipitation, heat waves and dry spells), significance and robustness were tested using a method adapted from Pfeifer et al. (2013). This method identifies regions with relatively strong and robust climate changes from an ensemble of climate change simulations. It can be applied to simulation results on regular model grids or to data aggregated onto larger regions. The robustness of the information given by the ensemble of climate projections is 
analysed using two statistical tests. The first test regards the agreement of the simulations in terms of the direction of the changes. In the second test, the significance of the projected changes in each simulation is assessed by applying the Mann-Whitney-Wilcoxon test. Only regions, which pass both tests, are identified as regions with robust projected changes.

The stringency of the tests can be adjusted by the choice of several parameters, for example the significance level, or by shifting the percentage of simulations, which have to pass the individual tests. We visualise the regions with relatively strong and robust climate changes. Regions with non-significant changes are treated in the same way as regions where the models strongly disagree on the direction of the changes. It is thus by purpose not possible to distinguish between regions where to a certain confidence no significant changes are projected to occur and regions where the projected changes cannot be given with sufficient confidence. Insignificant changes are not equivalent to the lack of agreement in the projected changes and should be interpreted differently, depending on the context.

First, the direction of change was assessed. Changes in regions in which more than $66 \%$ of the models agree in the direction of change were called robust changes. For the analyses of the significance, two different data preparation methods were used. For total precipitation and maximum, mean and minimum temperature, one value each per year and grid box was calculated (30 values per simulation per grid box). For heat waves, dry spells and heavy precipitation, only one value exists for each simulation and grid box, since they are defined over a 30-year period. Again they were calculated for all three time periods. For significance testing, the Mann-Whitney-Wilcoxon test was applied to the entire ensemble data set for the respective time periods.

For the climate change signal of mean annual temperature and total annual precipitation, a spatial correlation is calculated for the respective parameters of the SRES A1B and RCP8.5 simulation results for the end of the century based on the five sub-regions. For this analysis, all parameters for both scenarios were remapped to the ENSEMBLES grid with $25 \mathrm{~km}$ resolution.

\section{Definitions of impact-relevant indices}

In addition to the calculation of mean temperature and precipitation changes, we focussed on high-impact phenomena. Heavy precipitation, dry spells and heat waves were calculated according to the following definitions:

- "Heavy precipitation" is defined as the intensity of the heavy precipitation events defined as the 95th percentile of daily precipitation (only days with precipitation $>1 \mathrm{~mm} /$ day are considered).
- "Dry spells" are defined as periods of at least 5 consecutive days with daily precipitation below $1 \mathrm{~mm}$. The 95th percentile of the length of all identified dry spells is considered in this analysis and referred to as "extended dry spells."

- For the analysis of the change in number of heat waves, we used two different definitions. In the first definition, heat waves were considered as periods of more than three consecutive days exceeding the 99th percentile of the daily maximum temperature of the May to September season of the control period (1971-2000). The second definition, representing more extreme heat wave events, is based on the WMO definition (Frich et al. 2002). Heat waves were defined as periods of more than 5 consecutive days with daily maximum temperature exceeding the mean maximum temperature of the May to September season for the control period (1971-2000) by at least $5{ }^{\circ} \mathrm{C}$.

A range of indices was selected based on known climate impacts in Europe for infrastructure, agriculture and human health (Alcamo et al. 2007). The impact indices are calculated as means for 5 European sub-regions used in the European chapter of the forthcoming IPCC Fifth Assessment Report. The sub-regional classification is based on Metzger et al. (2005) (supplementary material, Fig. s1) and selected to represent 5 different climate and environmental characteristics: Alpine, Atlantic, Continental, Northern and Southern Europe. The list of impact index definitions is given in http://cccma.seos.uvic.ca/ETCCDI/list_27_indices. shtm.

For all ensembles, the "likely" range is defined as range within the 17 th and 83 rd percentile of projected changes.

\section{Results}

Mean changes of temperature and precipitation

To date, the regional climate change projections provided by the EU-FP6 ENSEMBLES multi-model ensemble for the SRES A1B scenario are considered as state-of-the-art for European climate impact research. Therefore, we compared this data set to the new regional EURO-CORDEX data set for RCP8.5 and RCP4.5. Figure 1 shows the ensemble mean of the mean annual temperature and total annual precipitation change until the end of the century. Figure $1 \mathrm{~b}, \mathrm{~d}$ shows a robust and statistically significant warming, with regional differences, in the range of $1-4.5{ }^{\circ} \mathrm{C}$ for RCP4.5 and of $2.5-5.5{ }^{\circ} \mathrm{C}$ for RCP8.5. These ranges encompass the warming range projected for the A1B scenario, where temperature increases between 3 and 


\section{RCP45}

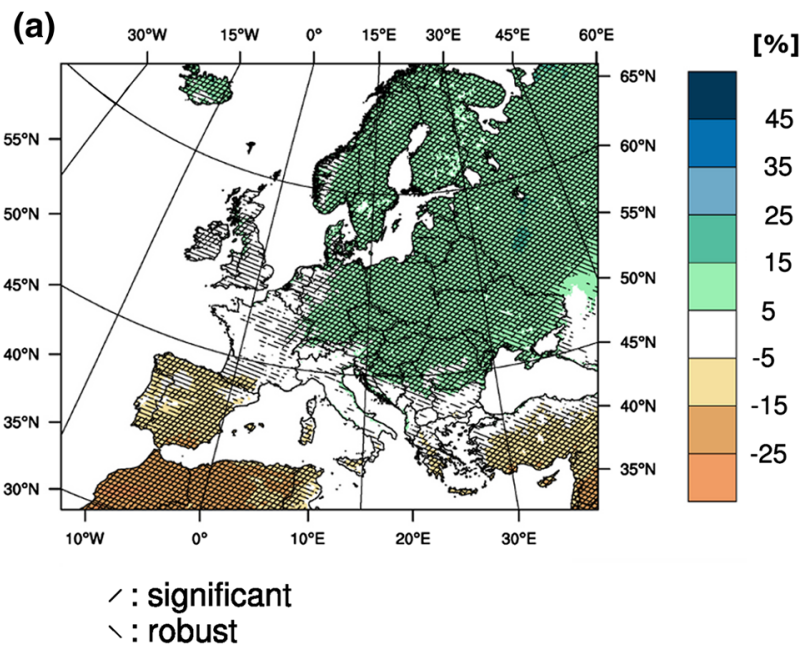

RCP85

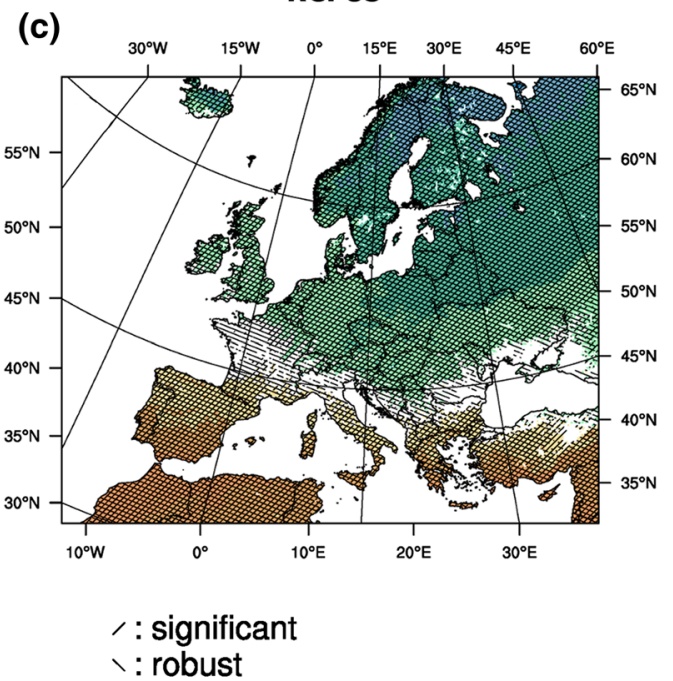

(e)

A1B

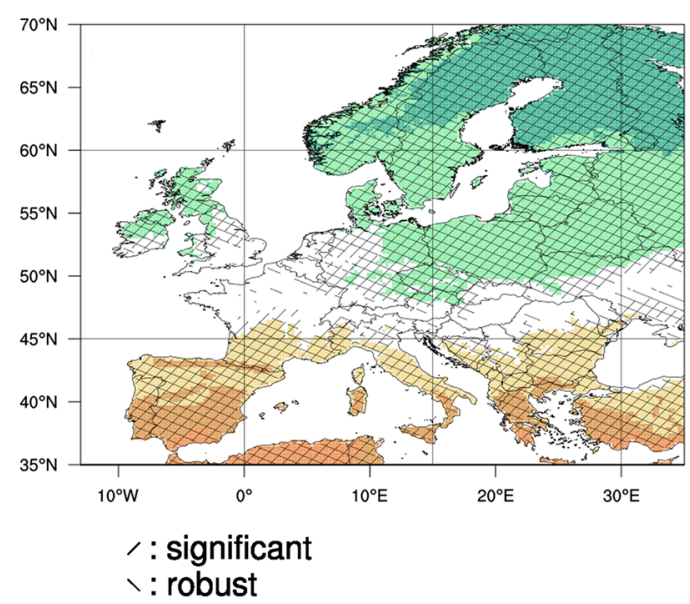

Fig. 1 Projected changes of total annual precipitation (\%) (left) and annual mean temperature [K] (right) for 2071-2100 compared to 1971-2000, for A1B (e, f), RCP8.5 (c, d) and RCP4.5 (a, b) scenarios.

\section{RCP45}

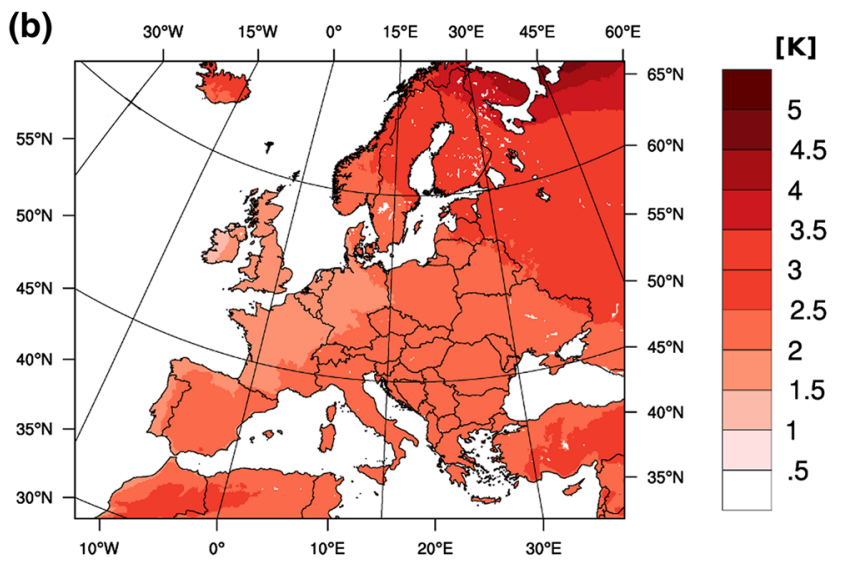

Changes are Significant Changes are Robust

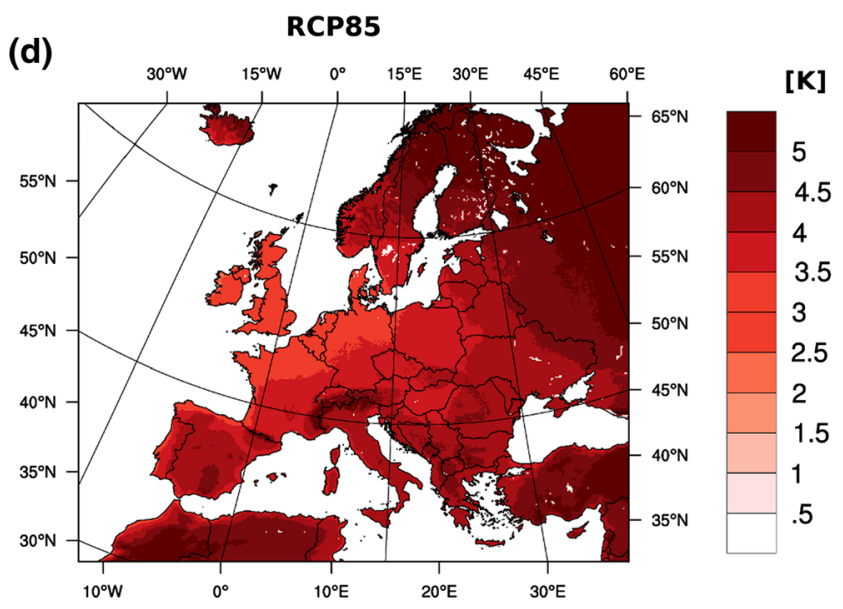

Changes are Significant Changes are Robust

(f)

A1B
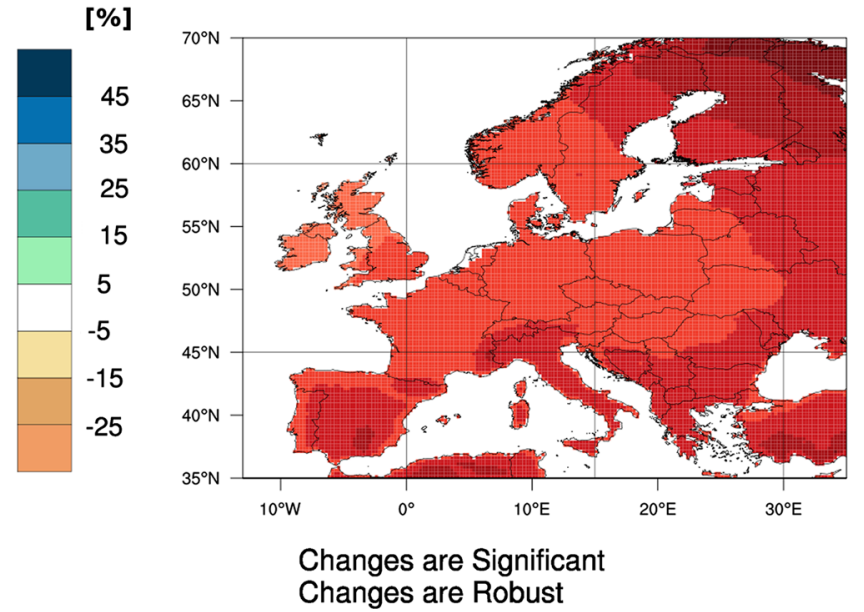

[K]

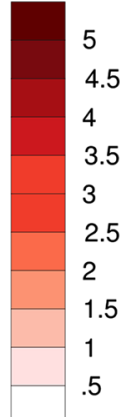

Hatched areas indicate regions with robust and/or statistical significant change (a, c, e). Changes are robust and significant across the entire European continent $(\mathbf{b}, \mathbf{d}, \mathbf{f})$ 
Table 1 Spatial correlation of SRES A1B and RCP8.5 emission scenarios for changes in mean annual temperature and annual total precipitation of the sub-regions for the time periods 2021-2050 and 2071-2100

\begin{tabular}{|c|c|c|c|c|}
\hline \multirow{3}{*}{$\begin{array}{l}\text { Spatial } \\
\text { correlation of } \\
\text { RCP8.5 and } \\
\text { SRES A1B }\end{array}$} & \multicolumn{4}{|c|}{ Climate parameter } \\
\hline & \multicolumn{2}{|c|}{$\begin{array}{l}\text { Mean annual } \\
\text { temperature }\end{array}$} & \multicolumn{2}{|c|}{$\begin{array}{l}\text { Annual total } \\
\text { precipitation }\end{array}$} \\
\hline & $2021-2050$ & $2071-2100$ & $2021-2050$ & $2071-2100$ \\
\hline Alpine & 0.88 & 0.95 & 0.92 & 0.94 \\
\hline Atlantic & 0.82 & 0.98 & 0.87 & 0.94 \\
\hline Continental & 0.94 & 0.96 & 0.72 & 0.92 \\
\hline Northern & 0.97 & 0.97 & 0.59 & 0.81 \\
\hline Southern & 0.90 & 0.89 & 0.71 & 0.96 \\
\hline
\end{tabular}

$4.5^{\circ} \mathrm{C}$ (Fig. 1f). The projected spatial patterns are very similar in all scenarios with greater annual mean warming in Southern Europe and towards the northeast. Under RCP8.5, large parts of Northern Scandinavia, Eastern Europe and the Alpine ridge might be exposed to a warming of more than $4.5^{\circ} \mathrm{C}$ compared to $1971-2000$, which could be avoided by RCP4.5.

Associated with the large increase in temperature in RCP8.5 are robust changes in annual precipitation. The ensemble mean projects a statistically significant increase in large parts of Central Europe and Northern Europe of up to about $25 \%$ and a decrease in Southern Europe. A zone with small changes, which are not significant (however, partially robust in the sign of change), indicates where the climate change signals change the sign (Fig. 1c, white areas). The pattern of the changes is very similar for RCP4.5, but less pronounced (Fig. 1a). The spatial pattern for A1B precipitation changes qualitatively agrees with the described changes for RCP4.5 and RCP8.5, and the magnitude of the changes mostly lies in-between the two RCPs. However, differences in the spatial patterns are seen over the British Isles, Benelux and Germany (Fig. 1e).

For mean temperature and precipitation change, a spatial correlation has been done between RCP8.5 and A1B results (Table 1). For all sub-regions, the spatial correlation between SRES A1B and RCP8.5 is very high, with $0.82-0.97$ for temperature changes and $0.59-0.92$ for precipitation changes depending on the region for mid-century. Towards the end of the century, the correlation is even stronger for both parameters.

Seasonal changes of mean temperature and precipitation are shown in the supplementary material (Fig. s2-s5). The seasonal temperature change signals show more regional heterogeneity than the annual mean. The zone between regions in which precipitation increases in the north and decreases in the south shifts southwards in summer and northwards in winter.
Seasonal mean changes for heavy precipitation

The projected seasonal mean changes in heavy precipitation for the three emission scenarios are relatively similar, but some regional differences are visible (Figs. 2 (RCP8.5), 3 (A1B), 4 (RCP4.5)). Most obvious differences are the increased regional detail in the RCP8.5 and $\mathrm{RCP} 4.5$, which is related to the higher horizontal resolution of about $12.5 \mathrm{~km}$ for the RCPs compared to $25 \mathrm{~km}$ for A1B, for which more homogeneous changes are calculated. The annual cycle of changes in heavy precipitation is similar in all three scenarios, but the amplitude of the change is stronger in RCP8.5 than in A1B in several regions. The results for RCP8.5 include a possible decrease in heavy summer precipitation by about $25 \%$ over some parts of the Iberian Peninsula and Southern France, accompanied by regional increases in parts of Spain and Portugal. For winter, RCP8.5 projects strongest increases in heavy precipitation (up to $35 \%$ ) in Central and Eastern Europe, whereas A1B projects changes up to $25 \%$ only in this region. Only for some parts in Scandinavia, A1B shows similar values as RCP8.5.

Important regional differences in heavy precipitation are projected for the RCP4.5 scenario. Compared to RCP8.5, the seasonal patterns of change are similar, but the amount of change is much smaller (up to $15 \%$ in large areas with isolated spots up to $25 \%$ ) and-besides isolated regions in Southern Europe (mostly along coastlines)—no decrease in heavy precipitation is indicated.

GCM simulations tend to underestimate the high precipitation intensities (Sun et al. 2006). An improved distribution of high precipitation intensities is an important advantage of regional climate simulations. Figure 5 shows the relative frequencies of daily precipitation intensities of an ensemble of five GCM simulations and the corresponding regional downscaling experiments for the reference period 1971-2000 analysed over a central land region of the EURO-CORDEX domain $\left(45^{\circ} \mathrm{N}-50^{\circ} \mathrm{N}\right.$ and $2^{\circ} \mathrm{E}-$ $\left.17^{\circ} \mathrm{E}\right)$. For this analysis, data from all grid cells were taken into account. The distribution illustrates that the GCMs generally produce more precipitation intensities with up to $12 \mathrm{~mm} /$ day. The RCMs, in contrast, show higher intensities. Strong intensities above $30 \mathrm{~mm} /$ day do hardly occur in the GCM simulations. Figure 6 shows the temporal changes of the precipitation frequencies between the near future period and the reference period for both scenarios and the GCM and the RCM ensembles. Striking is that both model types reduce the number of weak precipitation intensities below $9 \mathrm{~mm} /$ day in both scenarios and increase the relative frequencies in all higher intensity classes. This shift in daily precipitation intensities, however, turns out much more moderate in the RCM than in the GCM simulations of both scenarios, the RCP4.5 and the RCP8.5. 

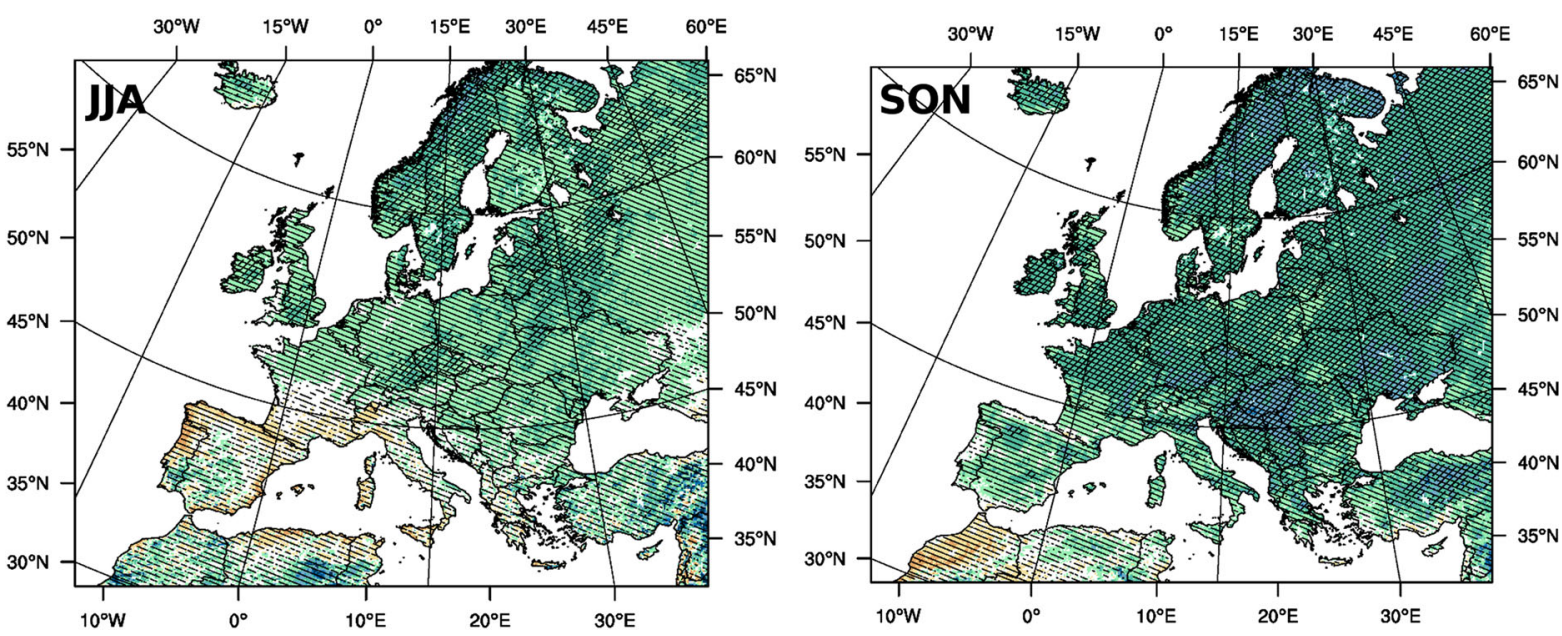

[\%]

: significant

$\checkmark$ : robust
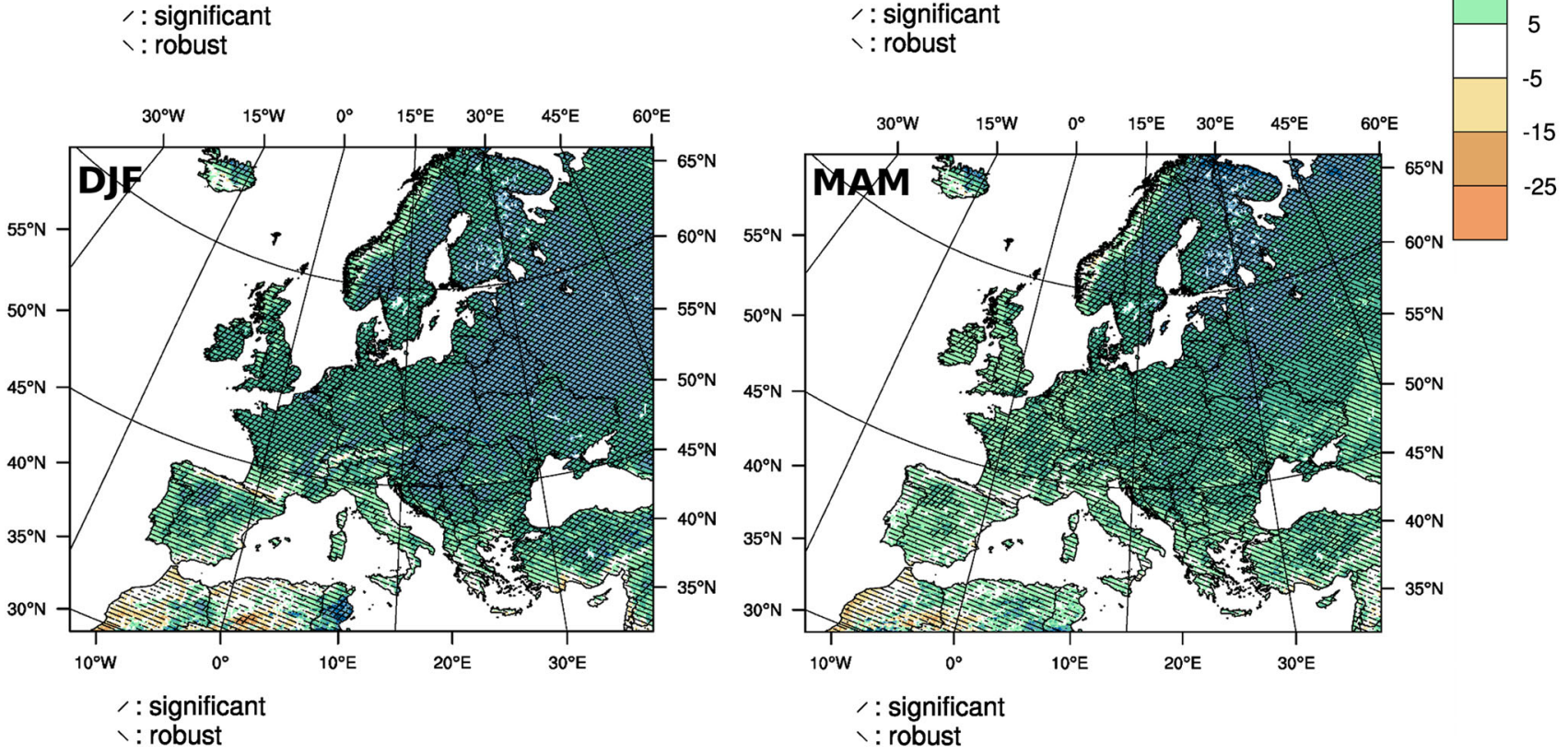

Fig. 2 Projected seasonal changes of heavy precipitation (\%) based on the RCP8.5 scenario for 2071-2100 compared to 1971-2000. Hatched areas indicate regions with robust and/or statistical significant change

The frequency changes of the RCM simulations are especially in the range between 10 and $20 \mathrm{~mm} /$ day less than half of the GCM changes. Above $30 \mathrm{~mm} /$ day, however, the increase in the RCM ensembles exceeds the climate change signal of the GCMs. Figure 6 also demonstrates that both effects - the reduction in weak intensities and the increase in strong intensities-are more pronounced in the RCP8.5 scenario. The analyses of the processes leading to the different behaviour are beyond the scope of this paper and will be studied in a separate paper.

This analysis proves two effects of an increased resolution, which can be regarded as an added value of regional climate simulations. On the one hand, the RCMs provide higher daily precipitation intensities, which are completely missing in the GCM simulations, and on the other hand, they provide a significantly different climate change of daily precipitation intensities resulting in a smoother shift from weak to moderate and high intensities.

Mean length of dry spells

Projected changes in the 95th percentile of the mean length of dry spells are shown in Fig. 7 for A1B (top), RCP8.5 (middle) and RCP4.5 (bottom) for 2021-2050 and 2071-2100 with respect to 1971-2000. For the early period, the change patterns are very similar in all scenarios (left row), although the number of simulations taken into account for each scenario ensemble is different. Beside some common features in South-West Europe, substantial differences in the projected changes for dry spells lengths 

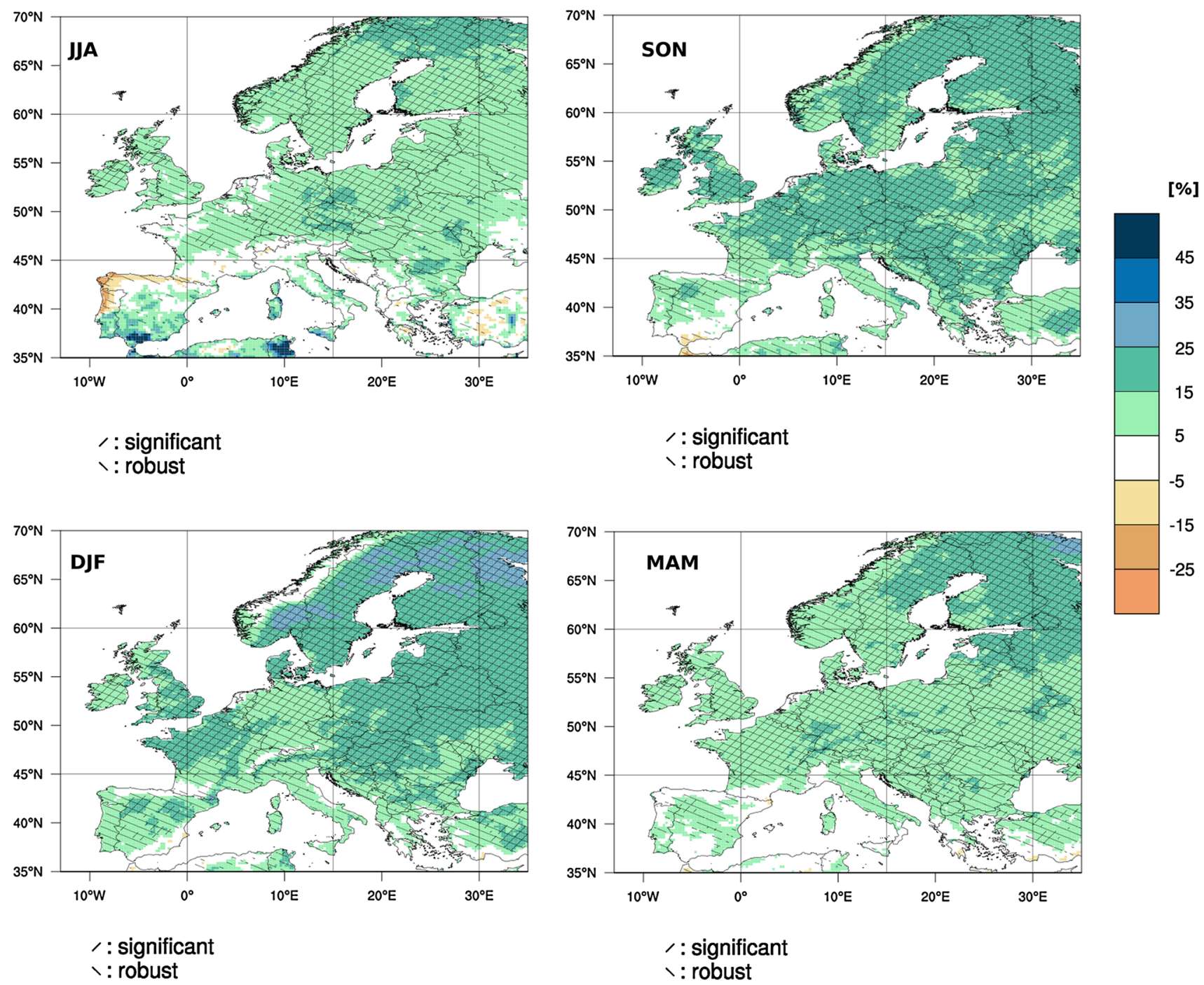

Fig. 3 Projected seasonal changes of heavy precipitation (\%) based on the A1B scenario for the period 2071-2100 compared to 1971-2000. Hatched areas indicate regions with robust and/or statistical significant change

are visible until 2100. For RCP4.5 and A1B, a small increase in the length of extended dry spells is projected for Central Europe, which is more pronounced in A1B. A decrease in the length of extended dry spells is calculated in A1B for parts of Scandinavia. This feature is extended towards the Alps in the RCP8.5, in which the number of dry spells increases (not shown). This means that under RCP8.5 more but shorter dry spells are projected in the alpine region. For regions with a large increase in the length of extended dry spells, the number of dry spells is decreasing (not shown).

Mean number of heat waves

Projected changes in the mean number of heat waves during May-September are presented in Fig. 8, for RCP4.5 and RCP8.5, for the two future time periods and for two different definitions of heat waves. From the upper four panels, displaying the p99-heat wave definition, it is obvious that with less warming (see "Mean changes of temperature and precipitation" section) in RCP4.5, the increase in number of heat waves is smaller than in RCP8.5. This is more pronounced towards the end of the century (Fig. 8c, d) than for the earlier time period (Fig. 8a, b). For both scenarios, the increase is strongest in Southern Europe, but towards the end of the century the number of heat waves increases all over Europe. The number of heat waves for Southern Europe is projected to increase by more than 45 . The increase is mostly robust and significant. The change in the number of heat waves considerably depends on the definition (thresholds and duration), which is used. Therefore, a second definition was 

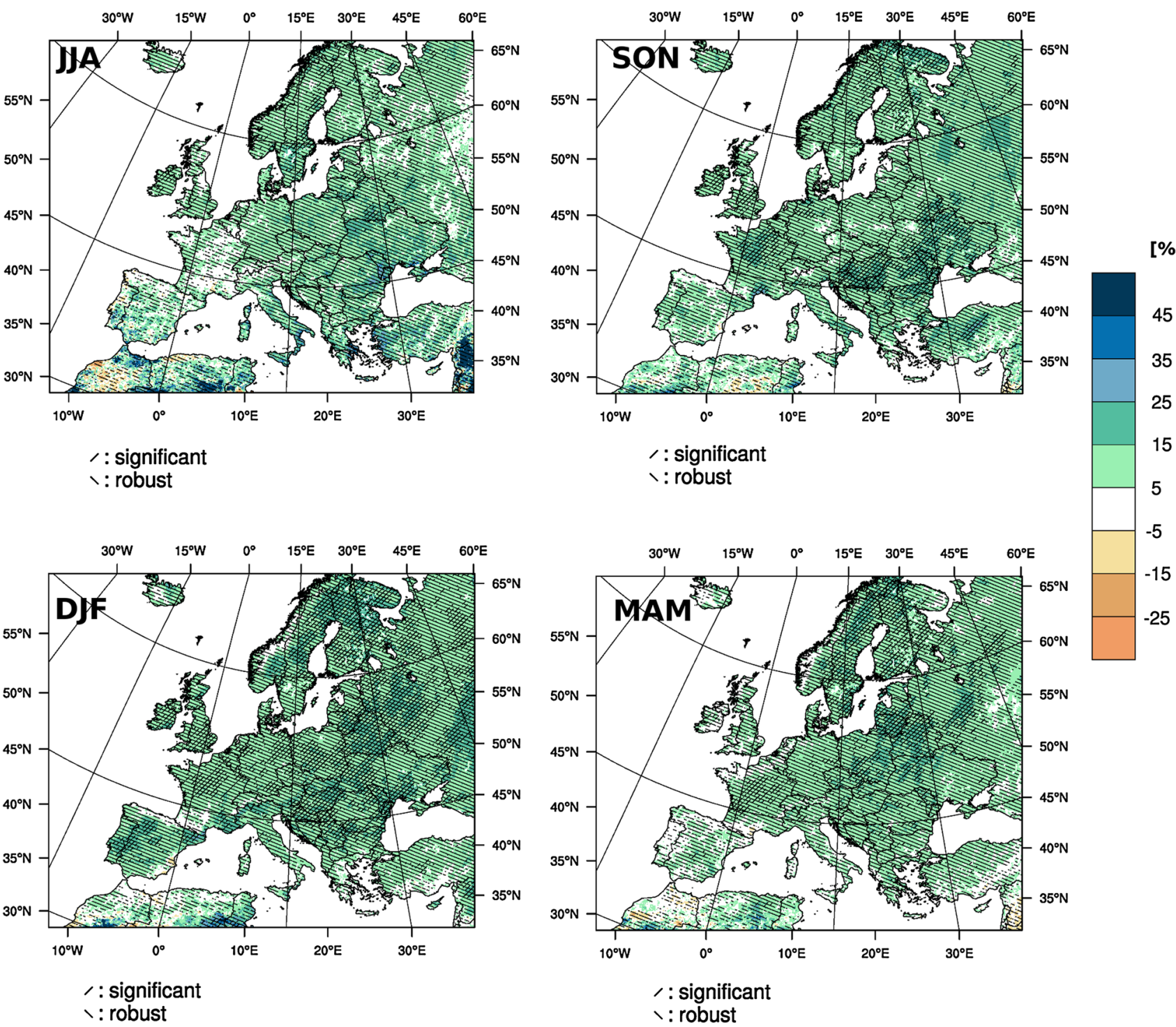

Fig. 4 Projected seasonal changes of heavy precipitation (\%) based on the RCP4.5 scenario for the period 2071-2100 compared to 1971-2000. Hatched areas indicate regions with robust and/or statistical significant change

used based on that developed by the World Meteorological Organization (see "Definitions of impact-relevant indices" section). Under this definition, the increase in the mean number of heat waves is much less (Fig. 8e, f). For the WMO-heat wave definition not a single heat wave is detected in the ensemble mean for the reference period as well as for mid of the century, because the criteria are much stricter. Also the duration of the heat wave is two days longer than in the p99-heat wave definition. For RCP8.5, meaning under the strongest projected warming, towards the end of the century, an increase is only projected for some parts of Southern Europe with additional 5 to more than 9 heat waves. The increase is significant and robust south of $55^{\circ}$ latitude.
Indices by sub-region

Projected changes of several impact indices, which could be of interest for impact studies in different sectors, are listed in Tables 2 (A1B) and 3 (RCP4.5 and RCP8.5) for the 5 sub-regions. For all sub-regions and indices, the median shifts into the same direction, independent of the scenario. For almost all indices, a substantially larger change in the median is projected in RCP8.5, compared to RCP4.5, however, the likely ranges frequently overlap. Exceptions to this are annual total precipitation in the Atlantic and Continental sub-regions, tropical nights in the Northern sub-region and the cold spell duration everywhere. Here the projected changes in RCP4.5 and RCP8.5 


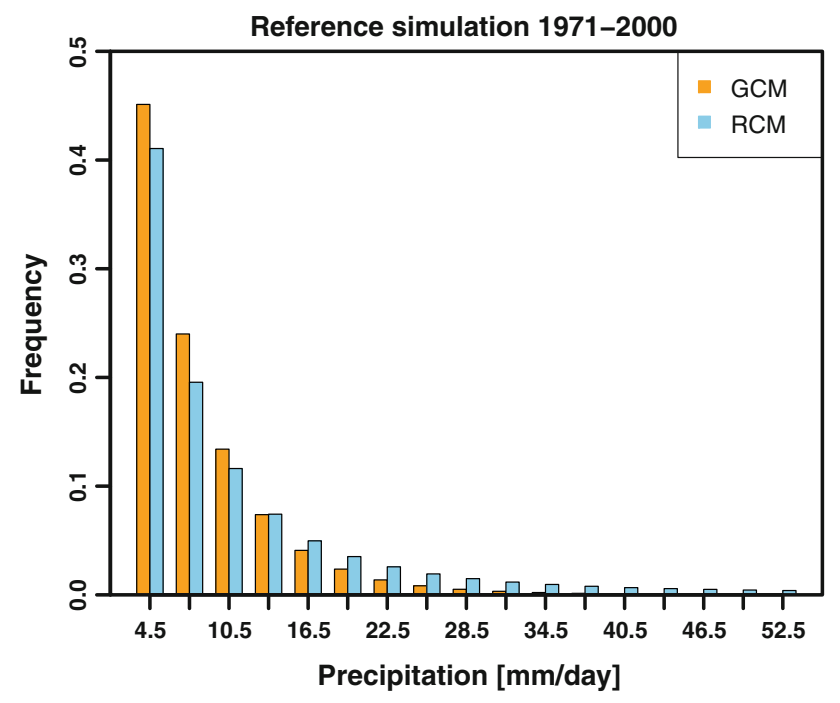

Fig. 5 Frequencies of daily precipitation intensities of an ensemble of five GCM simulations and the corresponding RCMs for the reference period 1971-2000 over a central land region of the EUROCORDEX domain $\left(45^{\circ} \mathrm{N}-50^{\circ} \mathrm{N}\right.$ and $\left.2^{\circ} \mathrm{E}-17^{\circ} \mathrm{E}\right)$

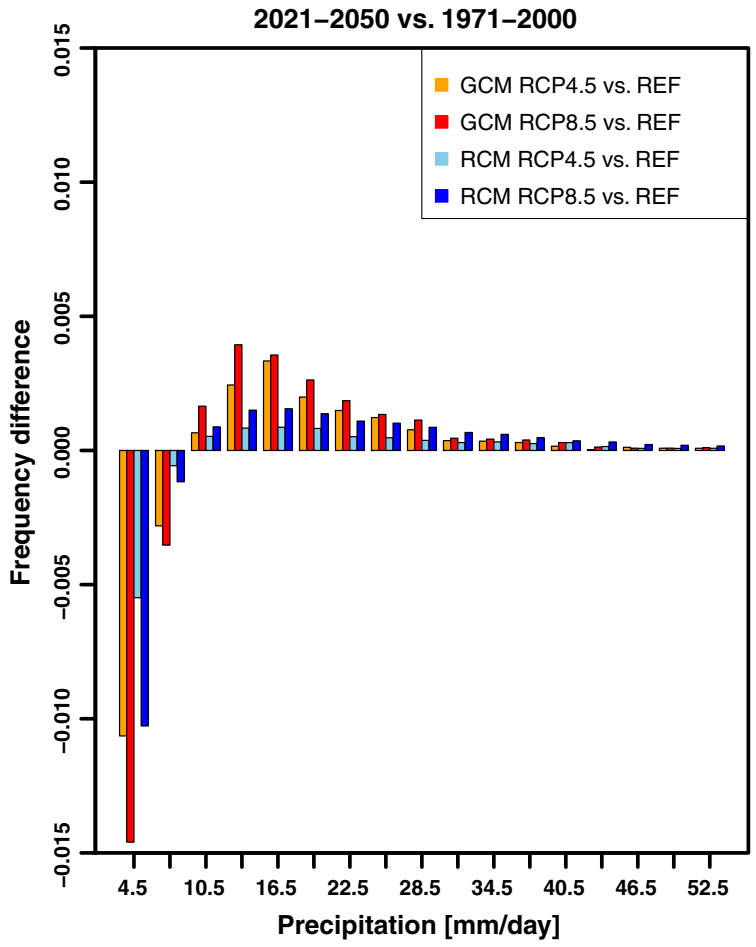

Fig. 6 Temporal changes of the precipitation frequencies between the near future period (2021-2050) and the reference period (1971-2000) for RCP4.5 and RCP8.5 and the GCM and the RCM ensembles

are rather similar. Differences between the RCP scenarios are most pronounced for growing season length and warm spell duration index, with no overlap between the likely ranges over all sub-regions (even the full range seldom overlaps).
The median change in A1B is generally centred within RCP4.5 and RCP8.5. For some cases like annual total precipitation in the Southern sub-region or tropical nights in the Atlantic, Northern and Southern sub-regions, however, the median change in A1B is even stronger than the median change in the RCP8.5 and only for change in annual total precipitation in the Continental sub-region, the median change in A1B is lower than the median change in RCP4.5. The spreads of the projected changes defined as the likely ranges are generally the same between RCP4.5 and RCP8.5 or slightly larger in RCP8.5. Exceptions to this are frost days in the Continental sub-region, tropical nights in the Northern sub-region and total rainfall amount above the 99th percentile of daily rain (wet days only) in the Southern sub-region. Here the likely ranges of projected changes are larger in the RCP4.5 scenario.

\section{Conclusions and outlook}

Regional climate change patterns for Europe projected by the high-resolution regional climate change ensemble within the EURO-CORDEX initiative for the new emission scenarios RCP4.5 and RCP8.5 have been compared to the state-of-the-art regional climate change data set from ENSEMBLES. The overall spatial patterns for temperature and precipitation changes and related indices are similar. There is a large degree of consistency between the ensembles of the three emission scenarios. The results clearly strengthen the previous findings obtained from the ENSEMBLES data set; however, there are some important new findings.

Climate projections from the new ensemble indicate a reduced northwards shift of Mediterranean drying evolution and slightly stronger mean precipitation increases over most of Europe. This is consistent with the two evaluation papers by Vautard et al. (2013) and Kotlarski et al. (2013), for reanalysis-driven hindcast simulations, where it was found that higher resolution leads to more precipitation in the climate models.

The high-resolution in the EURO-CORDEX simulations is clearly visible in the change pattern for heavy precipitation events. This spatial information is potentially very useful for climate impact studies. The more detailed spatial patterns in the high-resolution simulations can be related to better resolved physical processes like convection and heavy precipitation, and due to better representation of surface characteristics and their spatial variability. This needs to be elaborated further to understand the physical processes involved and the robustness of the pattern.

For some regions, especially the Alps, a connection between the changes in length of extended dry spells and the number of all dry spells (not only the longest ones) is 

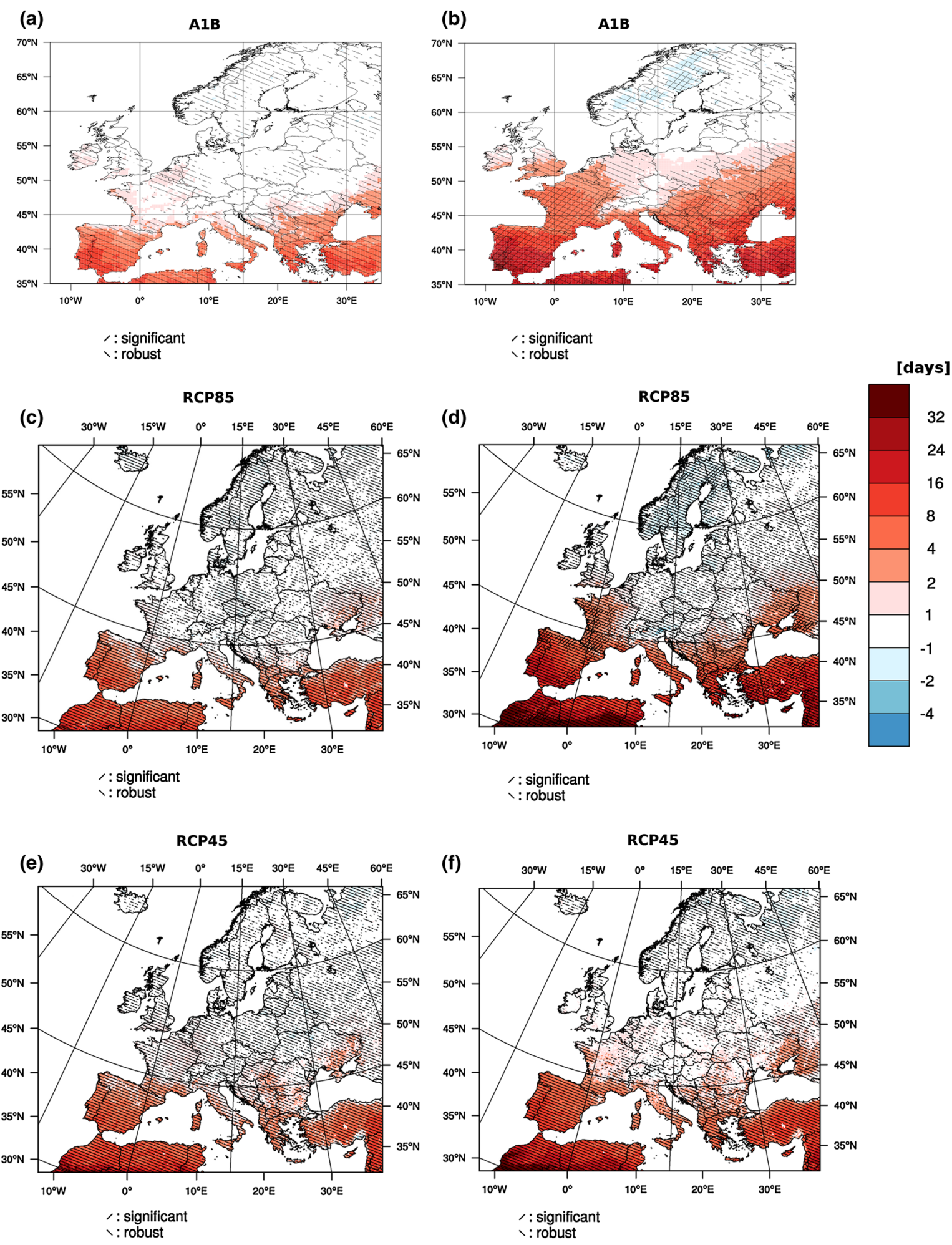

Fig. 7 Projected changes in the 95th percentile of the length of dry spells (days) for 2021-2050 compared to 1971-2000 (a, c, e) and (c, d) and RCP4.5 (e, f) scenarios. Hatched areas indicate regions with robust and/or statistical significant changes 
(a)

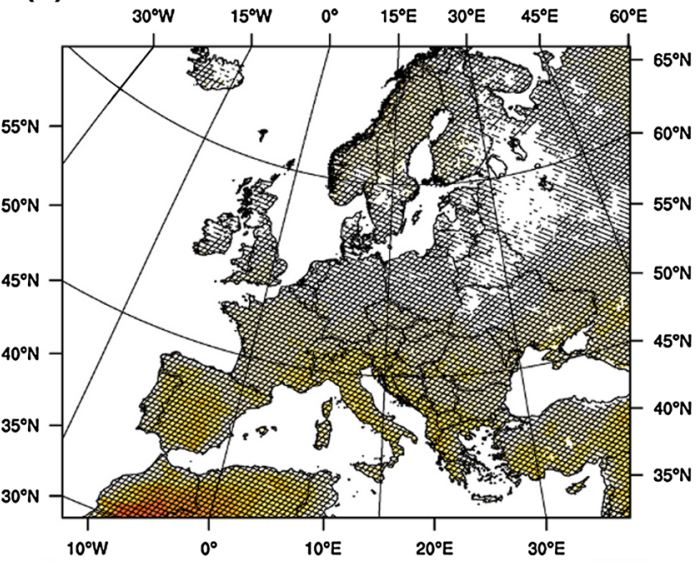

, : significant

: robust

(c)

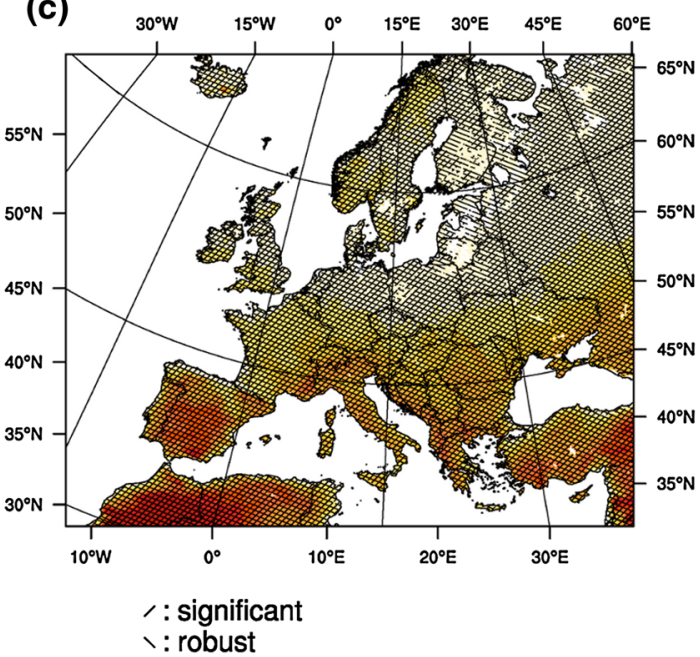

(e)

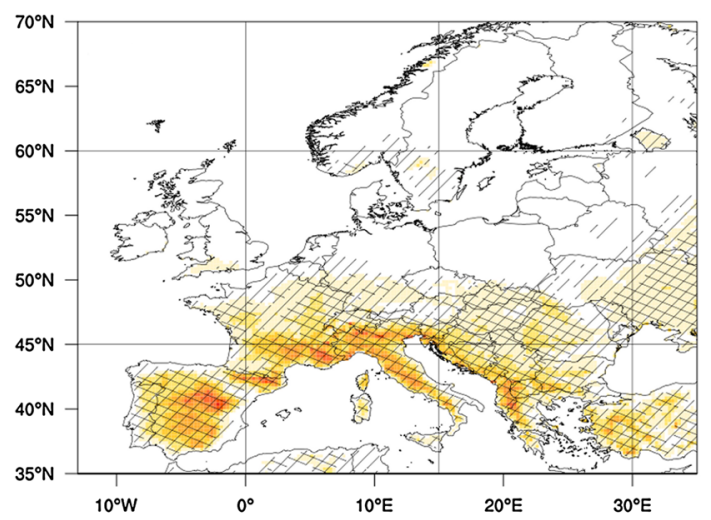

, : significant

$\checkmark$ : robust

\section{(b) $\mathrm{RCP85}$}

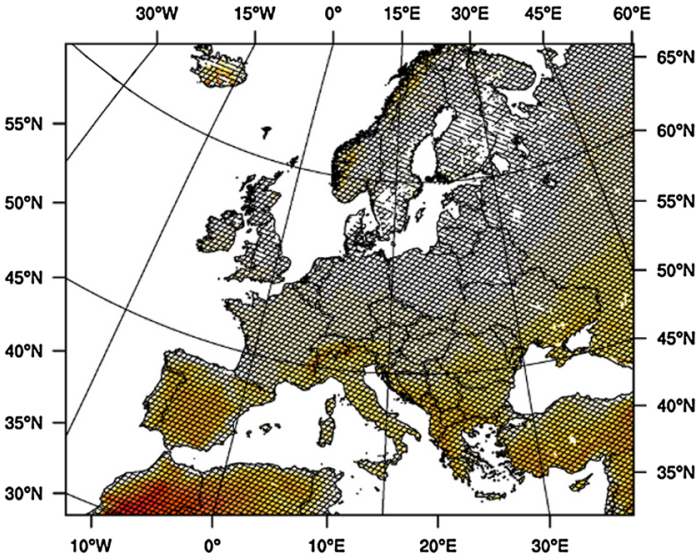

, : significant

: : robust

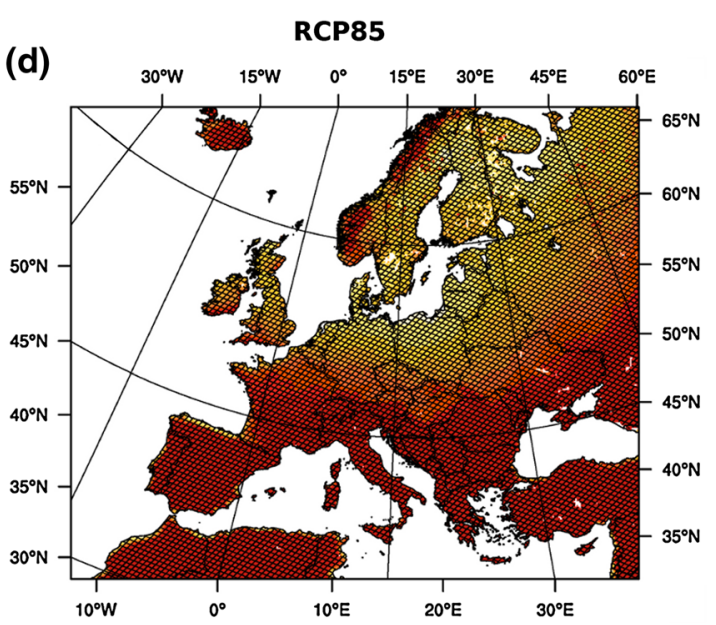

$<$ : significant

1: robust
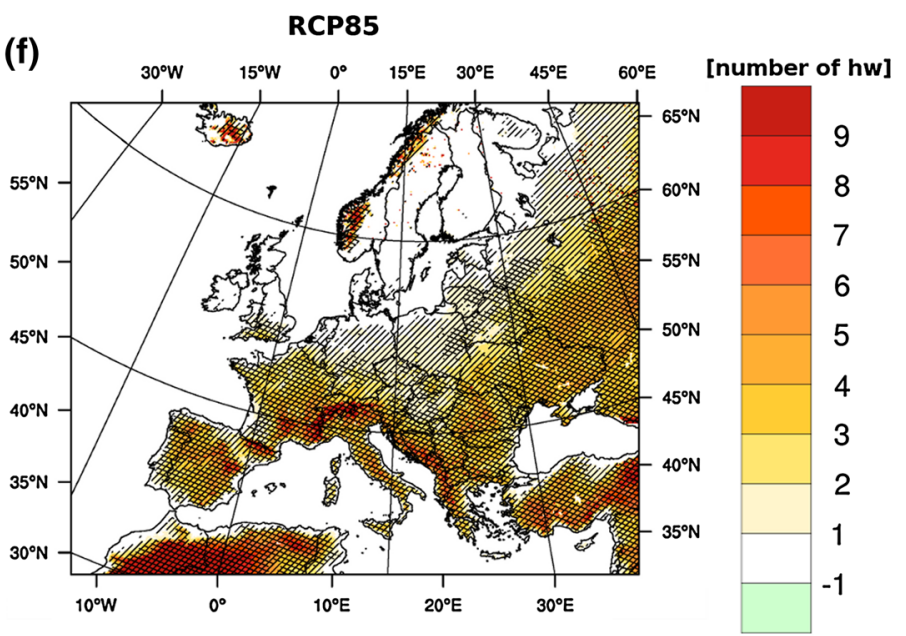

1 : significant

: robust [number of hw]

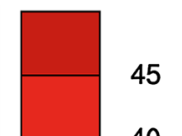

40

35

30

25

20

15

10

5

$-5$

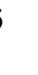

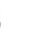

(n)


4 Fig. 8 Projected changes in the mean number of heat waves occurring in the months May-September for 2021-2050 compared to 1971-2000 (a, b) and 2071-2100 compared to 1971-2000 (c through f). Heat waves in figures a through $\mathbf{d}$ are defined as periods of more than 3 consecutive days exceeding the 99th percentile of the daily maximum temperature of the May to September season for the control period (1971-2000). Heat waves in figures $\mathbf{e}$ and $\mathbf{f}$ are defined as periods of more than 5 consecutive days with daily maximum temperature exceeding the mean maximum temperature of the May-September season for the control period (1971-2000) by at least $5{ }^{\circ} \mathrm{C}$. They are based on A1B emission scenario (e), the RCP8.5 $(\mathbf{b}, \mathbf{d}, \mathbf{f})$ and the RCP4.5 (a, c). Hatched areas indicate regions with robust and/or statistical significant change detected. In this region, the decreasing length of extended dry spells is linked to an increasing number of all dry spells. This seems to be plausible, but follow-up studies are needed to understand the governing processes.

The investigation related to possible changes in heat waves shows clearly that the definition of the heat wave is dominating the regional change pattern more than the differences in scenarios or time periods. Therefore, it is of utmost importance to clearly define the index in the light of the specific study and most likely for the sector of interest.

Table 2 Projected changes of selected climate parameters and indices for 2071-2100 with respect to 1971-2000 spatially averaged for European sub-regions for A1B scenario

\begin{tabular}{|c|c|c|c|c|c|c|c|}
\hline Scenario A1B & Climate parameters & Measure & Alpine & Atlantic & Continental & Northern & Southern \\
\hline \multirow[t]{36}{*}{ 2071-2100 minus 1971-2000 } & \multirow{4}{*}{$\begin{array}{l}\text { Mean annual } \\
\text { Temperature in } \mathrm{K}^{* *}\end{array}$} & Median & 3.4 & 2.5 & 3.3 & 3.8 & 3.6 \\
\hline & & Min & 2.8 & 1.9 & 2.1 & 3.2 & 2.3 \\
\hline & & Likely in the range & $3.1-4.5$ & $2.1-3.5$ & $2.8-4.5$ & $3.5-5.0$ & $3.3-4.1$ \\
\hline & & Max & 5.4 & 4.7 & 5.7 & 5.8 & 5.5 \\
\hline & \multirow{4}{*}{$\begin{array}{l}\text { Frost days (1) per } \\
\text { year* }\end{array}$} & Median & -50 & -24 & -44 & -54 & -24 \\
\hline & & Min & -37 & -13 & -26 & -38 & -12 \\
\hline & & Likely in the range & -38 to -57 & -15 to -34 & -27 to -53 & -40 to -55 & -12 to -31 \\
\hline & & Max & -72 & -39 & -56 & -71 & -34 \\
\hline & \multirow{4}{*}{$\begin{array}{l}\text { Summer days (2) per } \\
\text { year* }\end{array}$} & Median & 14 & 21 & 32 & 7 & 48 \\
\hline & & Min & 4 & 9 & 21 & 3 & 33 \\
\hline & & Likely in the range & $11-20$ & $16-32$ & $22-41$ & $5-14$ & $33-51$ \\
\hline & & Max & 21 & 34 & 43 & 27 & 51 \\
\hline & \multirow{4}{*}{$\begin{array}{l}\text { Tropical nights (4) per } \\
\text { year* }\end{array}$} & Median & 3 & 8 & 21 & 4 & 47 \\
\hline & & Min & 1 & 2 & 14 & 1 & 18 \\
\hline & & Likely in the range & $2-9$ & $6-17$ & $16-35$ & $1-7$ & $35-52$ \\
\hline & & Max & 11 & 32 & 43 & 10 & 60 \\
\hline & \multirow{4}{*}{$\begin{array}{l}\text { Growing season } \\
\text { length (5) days per } \\
\text { growing season** }\end{array}$} & Median & 47 & 41 & 52 & 41 & 36 \\
\hline & & Min & 27 & 23 & 20 & 25 & 14 \\
\hline & & Likely in the range & $34-56$ & $33-51$ & $33-62$ & $27-46$ & $27-41$ \\
\hline & & Max & 75 & 55 & 81 & 61 & 51 \\
\hline & \multirow{4}{*}{$\begin{array}{l}\text { Warm spell duration } \\
\text { index (14) days per } \\
\text { year* }\end{array}$} & Median & 57 & 44 & 42 & 67 & 91 \\
\hline & & Min & 46 & 29 & 26 & 37 & 67 \\
\hline & & Likely in the range & $51-84$ & $35-72$ & $37-69$ & $47-96$ & $85-112$ \\
\hline & & Max & 126 & 125 & 94 & 119 & 144 \\
\hline & \multirow{4}{*}{$\begin{array}{l}\text { Cold spell duration } \\
\text { index (15) days per } \\
\text { year* }\end{array}$} & Median & -5 & -5 & -6 & -6 & -5 \\
\hline & & Min & -4 & -4 & -4 & -5 & -3 \\
\hline & & Likely in the range & -4 to -5 & -4 to -6 & -5 to -6 & -5 to -8 & -4 to -5 \\
\hline & & Max & -8 & -9 & -9 & -9 & -8 \\
\hline & \multirow{4}{*}{$\begin{array}{l}\text { Annual total } \\
\text { precipitation (27) } \\
\text { in \%** }\end{array}$} & Median & 7 & 3 & 3 & 16 & -15 \\
\hline & & Min & 1 & 9 & -9 & 4 & -7 \\
\hline & & Likely in the range & $5-12$ & -4 to 5 & -1 to 5 & $13-21$ & -12 to -18 \\
\hline & & Max & 15 & -11 & 12 & 29 & -25 \\
\hline & \multirow{4}{*}{$\begin{array}{l}\text { Annual total } \\
\text { precipitation where } \\
\text { RR > 99p of } \\
1971 / 2000(26) \text { in } \\
\%^{* *}\end{array}$} & Median & 57 & 65 & 53 & 64 & 43 \\
\hline & & Min & 35 & 28 & 31 & 32 & 21 \\
\hline & & Likely in the range & $47-68$ & $42-98$ & $44-77$ & $47-88$ & $35-57$ \\
\hline & & Max & 117 & 112 & 110 & 105 & 74 \\
\hline
\end{tabular}

Numbers are based on 9 (indicated with*) and 20 (indicated with**) regional model simulations. The likely range defines the range of $66 \%$ of all projected changes around the ensemble median 


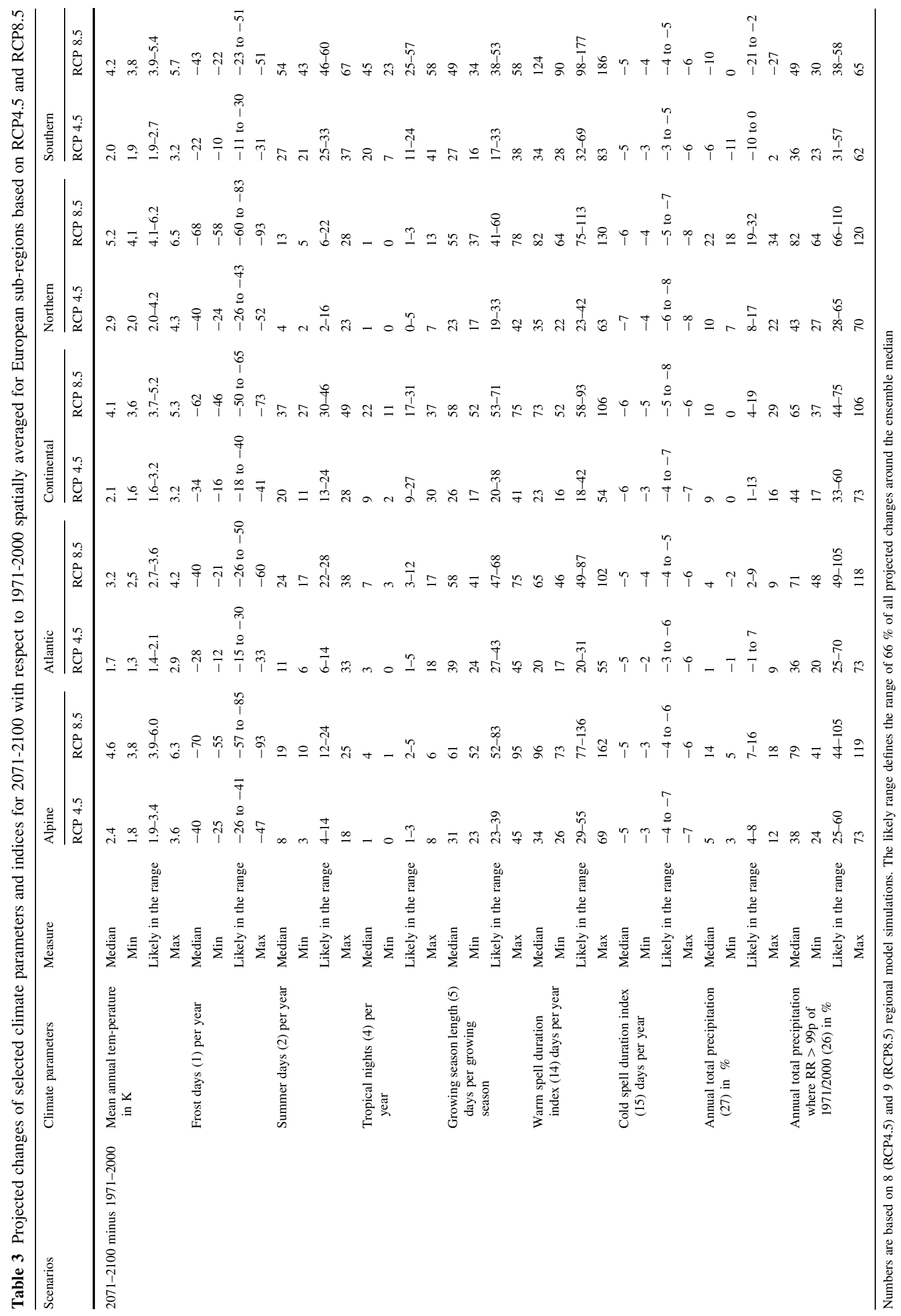


For example, the stricter (WMO) definition is more relevant to human health impacts. Any statement about possible changes in heat waves without this detailed information can easily be misleading regarding the risk of increases in future heat waves in Continental and Northern Europe.

The added value of regional climate simulations could be stated. RCMs provide higher daily precipitation intensities than GCMs, and they provide a significantly different climate change of daily precipitation intensities resulting in a smoother shift from weak to moderate and high intensities. Shifts of weak precipitation events are crucial for impact studies, in particular for hydrology, agriculture and air pollution.

The intention for this paper is not an in depth intercomparison of the time periods or scenarios, but the presentation of the new ensemble and a comparative analysis to currently used regional climate change information.

The EURO-CORDEX high-resolution data set will grow continuously and made available to the community. At the time of writing, more ensemble members are being conducted for both, the RCP4.5 and RCP8.5 scenarios. Most simulations will run until 2100 and will enlarge the ensemble. The EURO-CORDEX community agreed on common quality control and will provide a wealth of information for future climate research, impact assessment and adaptation.

Acknowledgments The ENSEMBLES data set used in this work was funded by the EU FP6 Integrated Project ENSEMBLES (Contract number 505539), whose support is gratefully acknowledged. Simulations at IPSL and INERIS were carried out thanks to the support of the CCRT/TGCC computing centre and allocation from the GENCI project on regional climate and air quality simulations over Europe. The CNRM-ALADIN simulations performed at MétéoFrance/CNRM were carried out in the frame of Med-CORDEX and HyMeX programs and can be downloaded at www.medcordex.eu, the Med-CORDEX database hosted at ENEA. The CCLM simulations were supported by the Federal Ministry of Education and Research (BMBF) and performed under the "Konsortial" share at the German Climate Computing Centre (DKRZ). The ETH Zurich simulations were supported by a Grant from the Swiss National Supercomputing Centre (CSCS) under project ID s78. The REMO simulations were supported by CSC, MPIM, as well as BMBF and performed under the "Konsortial" share at the German Climate Computing Centre (DKRZ), which we are further thankful for their various support. The KNMI-RACMO2 simulations were supported by the 7th Framework EU-projects IMPACT2C (FP7-ENV.2011.1.1.6-1 Grant Nr 282746) and ECLISE (FP7-ENV.2010.1.1.4-1 Grant Nr 265240), and by the Dutch Ministry of Infrastructure and the Environment. The subregions (see Figure s1) used in this study are a result of the work carried out as part of the Vulnerability Assessment of the EU funded Fifth Framework project ATEAM (Advanced Terrestrial Ecosystem Assessment and Modelling). Part of SMHI contribution was done in the Swedish Mistra-SWECIA programme founded by Mistra (the Foundation for Strategic Environmental Research).

Open Access This article is distributed under the terms of the Creative Commons Attribution License which permits any use, distribution, and reproduction in any medium, provided the original author(s) and the source are credited.

\section{References}

Alcamo J, Moreno JM, Novaky B, Bindi M, Corobov R, Devoy RJN, Giannakopoulos C, Martin E, Olesen JE, Shvidenko A (2007) Climate change 2007: Impacts, Adaptation and Vulnerability. In: Parry ML, Canziani OF, Palutikof JP, van der Linden PJ, Hanson CE (eds) Contribution of Working Group II to the Fourth Assessment Report of the Intergovernmental Panel on Climate Change. Cambridge University Press, Cambridge, UK, pp 541-580

Christensen OB, Christensen JH, Machenhauer B, Botzet M (1998) Very high-resolution regional climate simulations over Scandinavia-Present climate. J Climate 11:3204-3229

Colin J, Déqué M, Radu R, Somot S (2010) Sensitivity study of heavy precipitations in Limited Area Model climate simulation: influence of the size of the domain and the use of the spectral nudging technique. Tellus A 62:591-604. doi:10.1111/j.16000870.2010.00467.x

Frich P, Alexander LV, Della-Marta P, Gleason B, Haylock M, Klein Tank AMG, Peterson T (2002) Observed coherent changes in climatic extremes during the second half of the twentieth century. Clim Res 19:193-212. doi:10.3354/cr019193

Giorgi F, Jones C, Asrar GR (2006) Addressing climate information needs at the regional level: the CORDEX framework. Bulletin World Meteorol Organ 58:175-183

Herrmann M, Somot S, Calmanti S, Dubois C, Sevault F (2011) Representation of daily wind speed spatial and temporal variability and intense wind events over the Mediterranean Sea using dynamical downscaling: impact of the regional climate model configuration. Nat Hazards Earth Syst Sci 11:1983-2001. doi:10.5194/nhess-11-1983-2011

Hewitt CD, Griggs DJ (2004) Ensembles-based predictions of climate changes and their impacts. Eos 85:566

IPCC SRES (2000) In: Nakićenović N, Swart R (eds) Special Report on Emissions Scenarios: a special report of Working Group III of the Intergovernmental Panel on Climate Change. Cambridge University Press, UK

Jacob D, Elizalde A, Haensler A, Hagemann S, Kumar P, Podzun R, Rechid D, Remedio AR, Saeed F, Sieck K, Teichmann C, Wilhelm C (2012) Assessing the transferability of the regional climate model REMO to different coordinated regional climate downscaling experiment (CORDEX) regions. Atmosphere 3:181-199. doi:10.3390/atmos3010181

Kotlarski S, Keuler K, Christensen OB, Déqué M, Gobiet A, Görgen K, Jacob D, Lüthi D, van Meijgaard E, Nikulin G, Suklitsch M, Teichmann C, Vautard R, Warrach-Sagi K (2013) Regional climate modelling on European scales: a joint standard evaluation of the Euro-CORDEX RCM ensemble. Climate Dynamics. In prep

Kupiainen M, Samuelsson P, Jones C, Jansson C, Willén U, Hansson U, Ullerstig A, Wang S, Döscher R (2011) Rossby Centre regional atmospheric model, RCA4. Rossby Centre Newsletter, June

Meijgaard E van, Van Ulft LH, Lenderink G, de Roode SR, Wipfler L, Boers R, Timmermans RMA (2012) Refinement and application of a regional atmospheric model for climate scenario calculations of Western Europe. Climate changes Spatial Planning publication: KvR 054/12, ISBN/EAN 978-90-8815-046-3, pp 44

Metzger MJ, Bunce RGH, Jongman RHG, Muecher CA, Watkins JW (2005) A climatic stratification of the environment of Europe. Glob Ecol Biogeogr 14:549-563 
Moss RH, Edmonds JA, Hibbard KA, Manning MR, Rose SK, van Vuuren DP, Carter TR, Emori S, Kainuma M, Kram T, Meehl GA, Mitchell JFB, Nakicenovic N, Riahi K, Smith SJ, Stouffer RJ, Thomson AM, Weyant JP, Wilbanks TJ (2010) The next generation of scenarios for climate change research and assessment. Nature 463:747-756. doi:10.1038/nature08823

Pfeifer S, Gobiet A, Hänsler A, Mudelsee M, Rechid D, Ries H, Teichmann C, Weber B, Jacob D (2013) Mapping the robustness of regional climate change information. J App Meteorol Climatol. In review

Rockel B, Will A, Hense A (2008) Special issue regional climate modelling with COSMO-CLM (CCLM). Meteorol Z 17:347348. doi:10.1127/0941-2948/2008/0309

Rogelj J, Meinshausen M, Knutti R (2012) Global warming under old and new scenarios using IPCC climate sensitivity range estimates. Nat Clim Change 2:248-253. doi:10.1038/NCLIMATE1385

Samuelsson P, Jones C, Willén U, Ullerstig A, Gollvik S, Hansson U, Jansson C, Kjellström E, Nikulin G, Wyser K (2011) The Rossby Centre Regional Climate Model RCA3: model description and performance. Tellus A 63:4-23. doi:10.1111/j.1600-0870.2010. 00478.x

Skamarock WC, Klemp JB, Dudhia J, Gill DO, Duda DMBMG, Huang X-Y, Wang W, Powers JG (2008) A description of the advanced research WRF version 3. NCAR Technical note 475
Sun Y, Solomon S, Dai A, Portmann RW (2006) How often does it rain? J Clim 19: 916-934. doi:10.1175/JCLI3672.1

Taylor K, Stouffer RJ, Meehl GA (2012) An overview of CMIP5 and the experiment design. Bull Am Meteorol Soc 93:485-498. doi: 10.1175/BAMS-D-11-00094.1

Van der Linden P, Mitchell JFB (eds) (2009) ENSEMBLES: climate change and its impacts: summary of research and results from ENSEMBLES project. Met Office Hadley Centre, Exeter

van Vuuren DP, Edmonds J, Kainuma M, Riahi K, Thomson A, Hibbard K, Hurtt GC, Kram T, Krey V, Lamarque J-F, Matsui T, Meinshausen M, Nakicenovic N, Smith SJ, Rose SK (2011) Representative concentration pathways: an overview. Climatic Change 109:5-31. doi:10.1007/s10584-011-0148-z

Vautard R, Gobiet A, Jacob D, Belda M, Colette A, Déqué M, Fernández J, García-Díez M, Goergen K, Güttler I, Halenka T, Karacostas T, Katragkou E, Keuler K, Kotlarski S, Mayer S, van Meijgaard E, Nikulin G, Patarčić M, Scinocca J, Sobolowski S, Suklitsch M, Teichmann C, Warrach-Sagi K, Wulfmeyer V, Yiou P (2013) The simulation of European heat waves from an ensemble of regional climate models within the EUROCORDEX project. Climate Dynamics. doi:10.1007/s00382-013$1714-\mathrm{z}$ 